\title{
The Relationship between Splenic Length and Age in Adult Nigerians
}

\author{
Peter E. Chime1, Bibiana Oti1, Wilfred O. Okenwa ${ }^{2}$ \\ ${ }^{1}$ Department of Medicine, Enugu State University of Science and Technology Teaching Hospital, Parklane, Enugu, Nigeria \\ ${ }^{2}$ Department of Surgery, Enugu State University of Science and Technology Teaching Hospital, Parklane, Enugu, Nigeria \\ Email: pe4chyme@yahoo.com
}

How to cite this paper: Chime, P.E., Oti, B. and Okenwa, W.O. (2020) The Relationship between Splenic Length and Age in Adult Nigerians. Journal of Biosciences and Medicines, 8, 121-127.

https://doi.org/10.4236/jbm.2020.84011

Received: March 3, 2020

Accepted: April 18, 2020

Published: April 21, 2020

Copyright (C) 2020 by author(s) and Scientific Research Publishing Inc. This work is licensed under the Creative Commons Attribution International License (CC BY 4.0).

http://creativecommons.org/licenses/by/4.0/ (c) (i) Open Access

\begin{abstract}
Background: The relationship between splenic size and age has been well studied in children but reports on adults have been inconsistent. In Nigeria, the relationship between splenic size and age as well as the inter-decade changes in splenic length in adults has not been adequately studied. Objectives: This study aimed at determining the relationship between splenic length and age in adult Nigerians. Methods: This is a retrospective study in which sonographic splenic lengths of adult Nigerians aged 30 years and above were correlated with age. The relevant data were obtained from the medical records of those who had ultrasound splenic examination for the purposes of medical check-up between December 2016 and December 2017. Results: There were 50 cases aged between 34 and 57 years, with a mean age of $42.76 \pm$ 7.73 years. Their spleens had normal shape and echotexture. The mean splenic length was $9.56 \pm 1.37 \mathrm{~cm}$. Splenic length correlated negatively with age and decreased from $9.79 \pm 1.00 \mathrm{~cm}$ in the fourth decade to $9.49 \pm 1.67 \mathrm{~cm}$ in the fifth decade and to $9.24 \pm 1.63 \mathrm{~cm}$ in the sixth decade. The mean splenic length of 9.56 recorded in these cases was relatively small when compared to the results by other workers who studied subjects of much younger age groups. Conclusion: The studied cases which were in the fourth, fifth and sixth decades of life had a relatively small mean splenic length. There was no significant change in splenic length with increasing age.
\end{abstract}

\section{Keywords}

Splenic Length, Age, Splenic Volume

\section{Introduction}

The relationship between splenic size and age has been well studied in children: 
splenic size increases with increasing age in children as shown by some studies [1] [2] [3]. In the case of adults, reports from past studies have not been consistent regarding the relationship between splenic size and age. For example, Deland [1] reported that splenic weight is relatively constant between the age of 30 years and 59 years, while Loftus and Metrewili [3] reported progressive decrease in splenic size with increasing age in adults. In Nigeria, the problem of the relationship between splenic size and age has not been adequately studied. Ehimwenma and Tagbo [4] reported absence of significant correlation between splenic length and age but did not address the problem of inter-decade changes in splenic length in adult Nigerians. In their own study, Ezeofor et al. [5] studied only children aged between 5 and 17 years but did not study adults. This study was aimed at determining the relationship between splenic length and age in Nigerian adults, as well as determining the inter-decade changes in splenic length in this age group.

Sex differences in the size of spleen exist as men have been reported to have a slightly larger spleen than women [3] [4] [6] [7]. Also, racial differences in the size of spleen have been reported [6] [8]. The spleen was also shown to be significantly larger in whites than in African-Americans [6]. Because of the racial differences in size of splenic size, Loftus and Metrewili [3] recommended an upper limit of $12 \mathrm{~cm}$ for the spleen in adult Chinese subjects as against the previously recommended 12 to $14 \mathrm{~cm}$.

In published studies, splenic weight splenic volume and splenic length had all been used to assess splenic size in the past [1] [2] [3] [6] [7]. Of the three, namely, splenic weight, splenic volume and splenic length, measurement of splenic length by ultrasonography is the easiest and less cumbersome. Autopsy study has also shown that splenic length determined by ultrasonography correlated strongly with actual splenic length, actual splenic volume and actual splenic weight [6], thus demonstrating the reliability of sonographic splenic length.

For practical purposes, splenic length is measured along the long axis of the spleen between the dome and the tip of the spleen. The reported splenic length in adults varies all over the world and also varies with age [3] [5].

The aim of this study was to determine the relationship between sonographic splenic length and age in adult Nigerians. The study was designed to concentrate on the age group 30 years and above in which Deland [1] found no significant change in splenic length, but in which Loftus and Metrewili [3] found progressive decrease in splenic size with increasing age.

\section{Materials and Methods}

This was a retrospective study on adult Nigerian subjects who had sonographic spleen examination at the Enugu State University of Science and Technology Teaching Hospital, Parklane, Enugu, Nigeria, between December 2016 and December 2017. The inclusion criteria for the cases retrieved for study include 1) age 30 years and above, 2) presentation at the hospital for sonographic splenic 
assessment for the purposes of routine medical examinations rather than as a laboratory investigation for a medical illness, 3 ) absence of sonographic evidence of splenic disease such as splenomegaly or abnormal echotexture. All the cases which met the inclusion criteria were enlisted for study and the necessary information was retrieved from the medical records of those subjects.

The cases which met the inclusion criteria were 50 in number, and they were only males. They were subdivided into those in the fourth decade (30 to 39 years), fifth decade ( 40 to 49 years) and sixth decade of life (50 to 59 years). Splenic lengths were compared in the three groups. Continuous variables such as age and splenic lengths were compared using analysis of variance (ANOVA). Bivariate correlation and linear regression models were employed in determining the relationship between splenic lengths and subjects' ages. Statistical product and service solutions (SPSS) software version 22 (IBM Statistics, IBM Corp, NY) and Microsoft Excel 2013 (Microsoft Corporation) were used for the analyses. The results were presented in tabular form and graphically. Statistical values with probabilities less than 0.05 were considered significant.

\section{Results}

The 50 cases were aged between 34 years and 57 years, with a mean age of $42.76 \pm$ 7.73 years, and a mean splenic length of $9.56 \pm 1.37 \mathrm{~cm}$. Out of the 50 cases, 23 were in their fourth decade, 14 were in their fifth decade and 13 were in their sixth decade (Table 1). All the spleen examined had normal shapes and echotexture with no focal lesion.

The mean length of the spleen was $9.79 \pm 1.00 \mathrm{~cm}$ in the fourth decade, which reduced to $9.49 \pm 1.67 \mathrm{~cm}$ in the fifth decade and which reduced further to $9.24 \pm$ $1.63 \mathrm{~cm}$ in the sixth decade. However, the differences were not statistically significant $(\mathrm{p}=0.512)($ Table 1$)$.

Splenic length correlated negatively with age, overall (regression coefficient $=$ $-0.043)$. See Figure 1. Also, the regression coefficient (B) increased negatively from the fourth decade $(-0.027)$ to the fifth decade $(-0.123)$ and then to the sixth decade (-0.298). See Table 2 and Figure 2.

The frequency of splenomegaly, defined as spleen length greater than $13 \mathrm{~cm}$, was zero among the 50 cases studied (Table 1).

Table 1. Comparison of the lengths of the spleen at different decades.

\begin{tabular}{cccccc}
\hline & $\begin{array}{c}\text { All the subjects } \\
(\mathbf{n}=\mathbf{5 0})\end{array}$ & $\begin{array}{c}\text { Fourth decade } \\
(\mathbf{n}=\mathbf{2 3})\end{array}$ & $\begin{array}{c}\text { Fifth decade } \\
(\mathbf{n}=14)\end{array}$ & $\begin{array}{c}\text { Sixth decade } \\
(\mathbf{n}=13)\end{array}$ & P-value \\
\hline $\begin{array}{c}\text { Mean age (years) } \\
\text { (range) }\end{array}$ & $\begin{array}{c}42.76 \pm 7.73 \\
(34-57)\end{array}$ & $\begin{array}{c}35.70 \pm 1.43 \\
(34-39)\end{array}$ & $\begin{array}{c}44.57 \pm 3.65 \\
(40-49)\end{array}$ & $\begin{array}{c}53.31 \pm 2.43 \\
(50-57)\end{array}$ & 0.000 \\
$\begin{array}{c}\text { Mean spleen } \\
\text { length (cm) } \\
\text { (range) }\end{array}$ & $\begin{array}{l}9.56 \pm 1.37 \\
(6.99-13.75)\end{array}$ & $\begin{array}{c}9.79 \pm 1.00 \\
(7.06-11.52)\end{array}$ & $\begin{array}{c}9.49 \pm 1.67 \\
(7.31-13.75)\end{array}$ & $\begin{array}{c}9.24 \pm 1.63 \\
(6.99-12.63)\end{array}$ & 0.512 \\
$\begin{array}{c}\text { Frequency of } \\
\text { splenomegaly }\end{array}$ & $0(0.0 \%)$ & $0(0.0 \%)$ & $0(0.0 \%)$ & $0(0.0 \%)$ & - \\
\hline
\end{tabular}


Table 2. Correlation of splenic length with age.

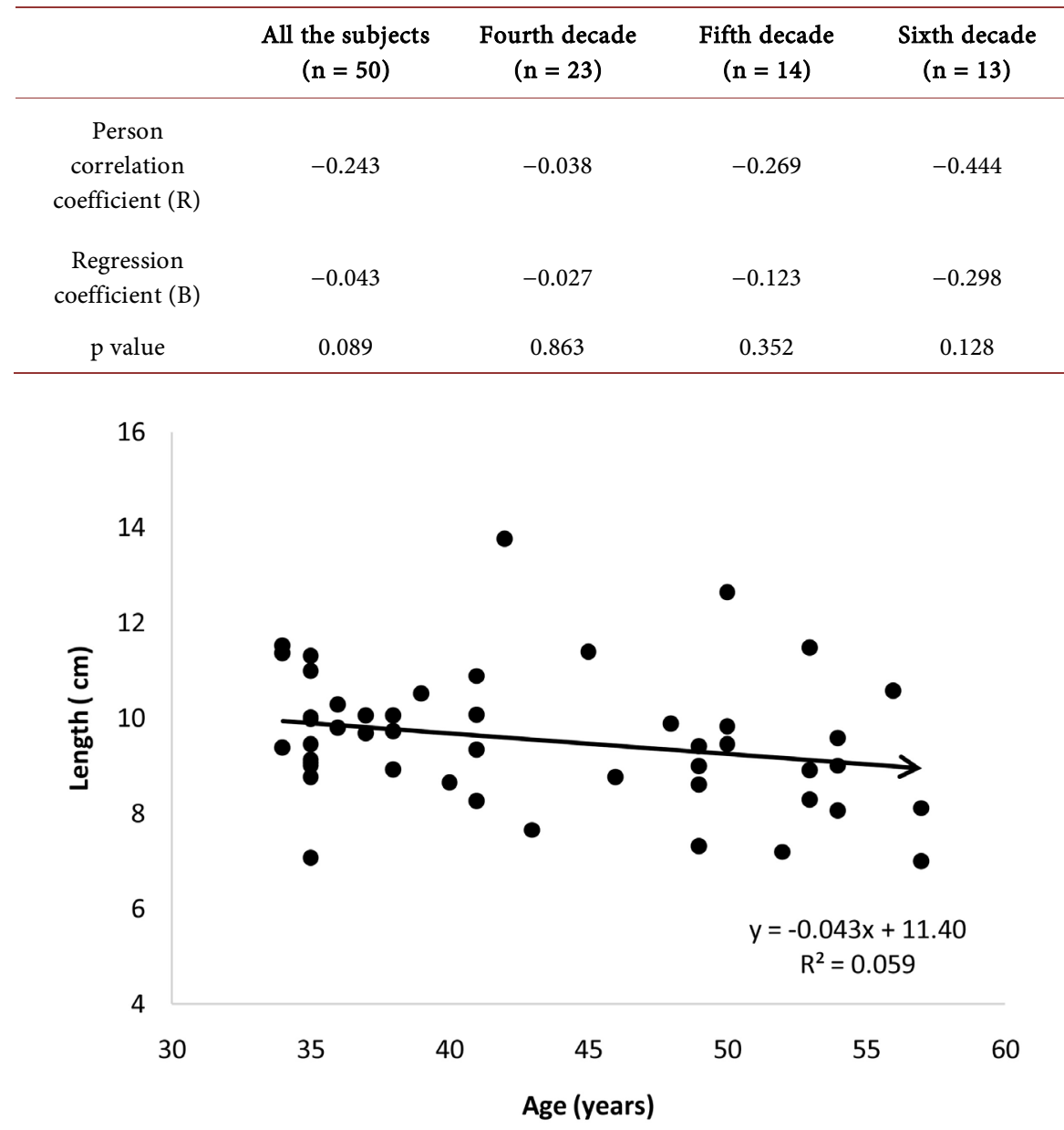

Figure 1. Scatter plots of splenic length versus age for all the 50 cases. Note the decreasing splenic length with increasing age (negative correlation).

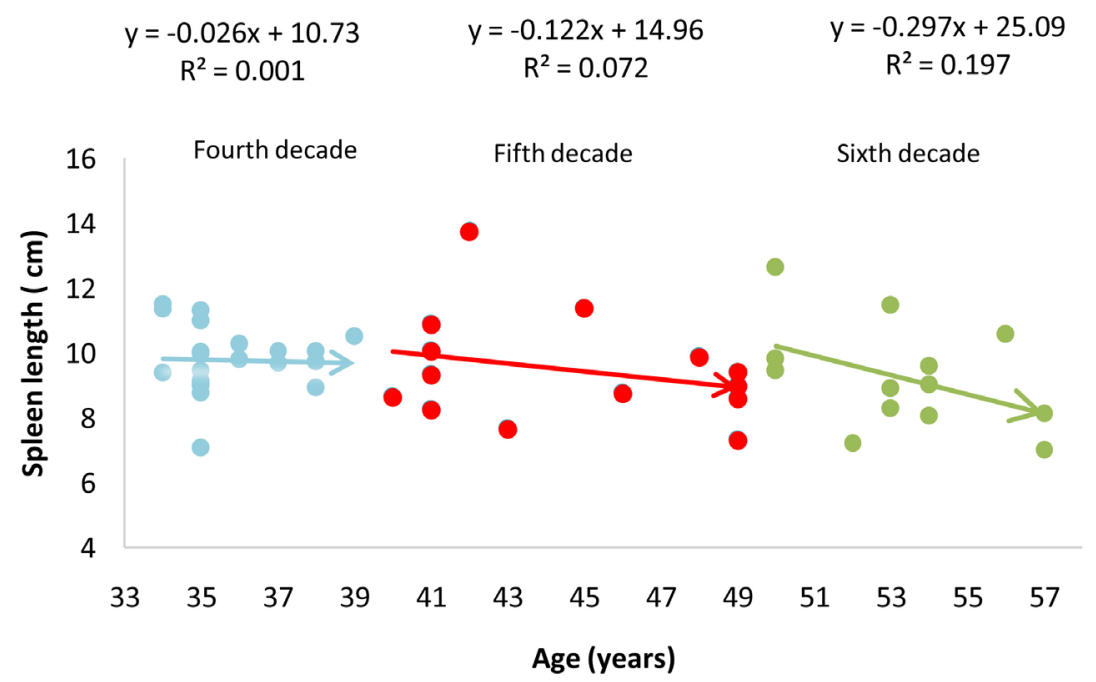

Figure 2. Scatter plots of splenic length versus age in the fourth decade (blue), fifth decade (red) and sixth decade (green) of life. Note the negative correlations. Note also that the line of best fit gets steeper with increasing decade. 


\section{Discussion}

The study examined the relationship between splenic length and age in adult Nigerian males in the fourth, fifth and sixth decades of life, who had a routine spleen examination. None of the spleens had sonographic evidence of any pathology. Study by Loftus et al. [8] has shown a very strong correlation between sonographic splenic length and actual or anatomic splenic length thereby demonstrating the reliability of sonographic splenic length.

The 50 cases in this study were aged between 34 and 57 years, with a mean age of $42.76 \pm 7.73$ years. Their mean splenic length was $9.56 \pm 1.37 \mathrm{~cm}$. This was less than the mean splenic length of $10.65 \mathrm{~cm}$ reported among collegiate athletes in the U.S.A. who were a much younger group with a mean age of 19.42 years [7]. Also, in another group of healthy athletes in the U.S.A. with a mean age of 19 years, Sppielman et al. [6] reported a mean splenic length of $10.3 \mathrm{~cm}$ among the girls and $11.4 \mathrm{~cm}$ among the boys. In a Turkish study sample aged between 17 to 42 years, with a mean age of 22.4 years, the reported mean splenic length was $10.76 \mathrm{~cm}$ [9]. In their own study, Rosenberg et al. [2] suggested $12.0 \mathrm{~cm}$ and $13.0 \mathrm{~cm}$ as the upper limits for girls and boys respectively, who were 15 years or older. In their own study in Nigeria, Ehimwenma and Tagbo [4] reported that a group of males with a mean age of 32.4 years had a mean splenic length of 11.1 $\mathrm{cm}$ while the women who had a mean age of 29.7 years had a mean splenic length of $10.1 \mathrm{~cm}$. These reports go on to show that the mean splenic length of $9.56 \mathrm{~cm}$ recorded in this study among adult males with a mean age of 42.76 years was small when compared to the mean splenic lengths recorded among those in younger age groups by other workers. Loftus and Metreweli [3] reported an even smaller splenic length in those above 80 years of age in which the splenic length was as small as $7.9 \mathrm{~cm}$ in men and $7.6 \mathrm{~cm}$ in women.

It is known that race and falciparum malaria endemicity can influence splenic size [10]. However, the study by Ehimwenma and Tagbo [4] which recorded a higher splenic length than observed in the current study was also carried out among people of the same race and people of co-residence in falciparum malaria endemic zone. The only difference was that the cases studied by Ehimwenma and Tagbo were a much younger age group than those used in the current study (mean age: 32.4 years versus 42.76 years).

As regards the inter-decade comparison of splenic length, splenic length correlated negatively with age in the cases studied suggesting that splenic length decreases with increasing age. The regression coefficient increased negatively from the fourth decade through the fifth decade to the sixth decade of life. However, the differences were not statistically significant, suggesting that the decline in splenic length with increasing age is not significant among the age group studied. This corroborated the findings of DeLand [1] which reported that splenic size was relatively constant between the ages of 30 years and 59 years which was also the age group covered in this study. However, the result of this study is at variance with that of Loftus et al. [8] which reported a progressive decrease in 
splenic length with increasing age.

\section{Conclusion}

The studied cases which were in the fourth, fifth and sixth decades of life, had a relatively small mean splenic length. The age-related decline in splenic length in this age group was not significant.

\section{Recommendation}

Future studies should address this problem using a longitudinal prospective study in order to see if the findings in this study can be corroborated.

\section{The Limitation of the Study}

The data used in this study were not longitudinal data.

\section{The Strength of the Study}

Only spleens with no sonographic evidence of splenomegaly or abnormal echotexture were used in this study.

\section{Conflicts of Interest}

The authors declare no conflicts of interest regarding the publication of this paper.

\section{References}

[1] DeLand, F.H. (1970) Normal Spleen Size. Radiology, 97, 589-592. https://doi.org/10.1148/97.3.589

[2] Rosenberg, H.K., Markowitz, R.I., Kolberg, H., Park, C., Bellah, R.D. and Hubbard, A. (1991) Normal Splenic Size in Infants and Children: Sonographic Measurements. American Journal of Roentgenology, 157, 119-121. https://doi.org/10.2214/ajr.157.1.2048509

[3] Loftus, W.K. and Metrewili, C. (1997) Normal Splenic Size in a Chinese Population. Journal of Ultrasound in Medicine, 16, 345-347. https://doi.org/10.7863/jum.1997.16.5.345

[4] Ehimwenma, O. and Tagbo, M.T. (2011) Determination of Normal Dimension of the Spleen by Ultrasound in an Endemic Tropical Environment. Archive of Nigerian Medical Journal, 52, 198-203. https://doi.org/10.4103/0300-1652.86141

[5] Ezeofor, S.N., Obikili,, E.N., Anyanwu, G.E., Onuh, A.C. and Mgbor, S.O. (2019) Sonographic Assessment of the Normal Limits of the Spleen in Healthy School Children in South-East Nigeria. Nigerian Journal of Clinical Practice, 17, 484-488. https://doi.org/10.4103/1119-3077.134046

[6] Spielmann, A.L., DeLong, D.M. and Kliewer, M.A. (2005) Sonographic Evaluation of Spleen Size in Tall Healthy Athletes. American Journal of Roentgenology, 184, 45-49. https://doi.org/10.2214/ajr.184.1.01840045

[7] Hosey, R.G., Mattacola, C.G., Kriss, V., Armsey, T., Quarles, J.D. and Jagger, J. (2006) Ultrasound Assessment of Spleen Size in Collegiate Athletes. British Journal of Sports Medicine, 40, 251-254. https://doi.org/10.1136/bjsm.2005.022376 
[8] Loftus, W.K., Chow, L.T. and Metreweli, C. (1999) Sonographic Measurement of Splenic Length: Correlation with Measurement at Autopsy. Journal of Clinical UItrasound, 27, 71-74.

https://doi.org/10.1002/(SICI)1097-0096(199902)27:2<71::AID-JCU4>3.0.CO;2-U

[9] Serter, S., Ceylan, C., Tunçyürek, Ö., Örgüç, S. and Pabuçcu, Y. (2010) Sonographic Evaluation of Spleen Size and Prevalence of Accessory Spleen in a Healthy Male Turkish Population. Turkish Journal of Hematology, 27, 25-28.

[10] Chauhan, R., Kapoor, V., Vohr, P.A., Jhala, P.J., Upadhyay, A.K. and Pathak, K.J. (1996) The Small Spleen in Malaria. Journal of Association of Physicians, India, 44, 483-485. 